\title{
Mechanical properties of concrete for radioactive waste repositories
}

\author{
Dana Koňáková ${ }^{1}$, Eva Vejmelková ${ }^{{ }^{*}}$, Vojtěch Pommer ${ }^{1}$, Lenka Scheinherrová ${ }^{1}$, Petr \\ Konvalinka ${ }^{2}$ and Robert Černý ${ }^{1}$ \\ ${ }^{1}$ Department of Materials Engineering and Chemistry, Faculty of Civil Engineering, Czech Technical \\ University in Prague, Thákurova 7, 16629 Prague 6, Czech Republic \\ ${ }^{2}$ Experimental Centre, Faculty of Civil Engineering, Czech Technical University in Prague, \\ Thákurova 7, 16629 Prague 6, Czech Republic
}

\begin{abstract}
Concrete casing for radioactive repositories have to meet many strict requirements. One of the most important is a radiation protection and a radionuclide inhabitation. Bentonite, with a great sorption capacity, seems to be a suitable material for this purpose. Therefore, the main aim of this study was to assess an impact of the bentonite utilization as a component in concrete mixtures. For this reason, basic physical properties and mechanical parameters of concretes containing different amount of bentonite were determined. Bentonite applications led to the open porosity growth, while the matrix densities were not influenced. Regarding the mechanical parameters, the compressive strengths as well as the flexural strengths were significantly deteriorated by the bentonite application. Despite the presented negative effect, the obtained results seems to prove a possible applicability of a lower percentage of bentonite in concrete structures not as a cement replacement, but just as a component.
\end{abstract}

\section{Introduction}

Global energy consumption is sharply increasing, and a nuclear power is one of the ways how to satisfy great demands of current society. Unfortunately, its utilization leads to a production of a radioactive waste, which has to be carefully handled and stored due to radiation's harmful impact on environment and organisms. It is necessary to eliminate radiation so much, so that environment would be exposed as little radiation as it possible. The basic safety standards are summarized in the council directive 2013/59/EURATOM [1], where the specific requirements for waste deposits differ according to radioactive activity, form of waste, half-life, etc. However, a common idea of a radioactive waste management is a creation of a multi barrier system with several protection levels. One of the barrier is usually composed of a concrete with superior durability. This concrete casing for a radioactive waste repositories have to provide many functions over its whole service life $[2,3,4]$. A radiation protection and a mitigation of a radionuclide release belong among the most important ones $[5,6]$, but this is a problematic issue to be addressed. The transport of radionuclides can be successfully inhibited by some sorption materials, for example in

* Corresponding author: eva.vejmelkova@,fsv.cvut.cz 
the form of natural clays or synthetic alternatives $[6,7,8]$. In this article, an admixture of bentonite is employed. This natural clay composes mostly of montmorillonite and it has many specific advantageous properties such as high sorption capacity, high cation exchange value, swelling and plasticity ability.

Also in the case of radioactive concrete casing, similar to all other building structures, mechanical properties belong among the most determining factors when considering the possible usage. This article is an initial study focused on mechanical properties of concrete based on blended cement with the future application as radioactive barriers. The main scope of this article is therefore to evaluate the applicability of bentonite as a concrete admixture, by means of the determination of basic physical and mechanical properties of several concrete mixtures. Specifically, the bulk densities, the matrix densities, the open porosities, the compressive strengths and the bending strengths belong among studied characteristics.

\section{Studied Materials}

Table 1 provides the material composition of studied concretes. As the main binder Portland cement CEM I 42.5 R (produced by Českomoravský cement, a.s., Mokrá) was selected. Except from the reference mixture RBR, bentonite B75 (Keramost a.s., Most) was added into the concrete as an admixture. This material composed of $65-80 \%$ montmorillonite and up to $7 \%$ of sodium carbonate. There were $10 \%\left(40 \mathrm{~kg} \mathrm{~m}^{-3}\right)$ of cement replaced by bentonite in all mixtures which was believed to take part in the pozzolanic reaction and the rest of bentonite was present as an inert admixture. The excess amount of bentonite admixture was increasing by $40 \mathrm{~kg} \mathrm{~m}^{-3}$ for each mixture, i.e. from $40 \mathrm{~kg} \mathrm{~m}^{-3}$ for RB1 to $120 \mathrm{~kg} \mathrm{~m}^{-3}$ for RB4. Silica flour ST6 (Sklopísek Střeleč a.s.) was used as a reference fine admixture, which amount was decreasing with growing amount of bentonite in the mixture. The reason for its application was also to complemented the granulometric curve of the whole mixtures. Chemical composition of mentioned fine components is presented in Table 2. The other components were same in all cases of studied mixtures: one fraction of fine aggregate (from CEMEX Czech Republic, s.r.o., gravel-pit Dobřín) two fractions of coarse aggregate (both from KÁMEN Zbraslav, a.s., Zbraslav), and Superplasticizer Stachement 2000 (STACHEMA CZ s.r.o.). Last remaining component was portable water, which was dosed in varying amount to achieve equal consistency of final mixtures.

All concrete mixtures were mixed at the same conditions, poured into moulds and cover with plastic sheets to diminish drying shrinkage. After one or two days the samples were demoulded and cured at laboratory conditions for 28 days. Before the conduction of experiments, the samples were cut into the required dimensions and dried.

Table 1. Material composition of studied concretes $\left(\mathrm{kg} \mathrm{m}^{-3}\right)$

\begin{tabular}{|l|c|c|c|c|c|}
\hline Component & RBR & RB1 & RB2 & RB3 & RB4 \\
\hline Portland cement CEM I 42.5 R & 400 & 320 & 320 & 320 & 320 \\
\hline Bentonite B75 & - & 80 & 120 & 160 & 200 \\
\hline Silica flour ST6 & 120 & 120 & 80 & 40 & - \\
\hline Aggregates 0-4 mm, Dobřín & 760 & 760 & 760 & 760 & 760 \\
\hline Aggregates 4-8 mm, Zbraslav & 455 & 455 & 455 & 455 & 455 \\
\hline Aggregates 8-16 mm, Zbraslav & 483 & 483 & 483 & 483 & 483 \\
\hline Superplasticizer Stachement 2000 & 6.9 & 6.9 & 6.9 & 6.9 & 6.9 \\
\hline Water & 195 & 165 & 160 & 160 & 160 \\
\hline
\end{tabular}


Table 2. Chemical composition of raw-materials [\%]

\begin{tabular}{|l|c|c|c|c|c|c|c|c|}
\hline Material & $\mathbf{S i O}_{\mathbf{2}}$ & $\mathbf{A l}_{\mathbf{2}} \mathbf{O}_{\mathbf{3}}$ & $\mathbf{F e}_{\mathbf{2}} \mathbf{O}_{\mathbf{3}}$ & $\mathbf{C a O}$ & $\mathbf{M g O}$ & $\mathbf{K}_{\mathbf{2}} \mathbf{O}$ & $\mathbf{N a}_{2} \mathbf{O}$ & $\mathbf{S O}_{\mathbf{3}}$ \\
\hline Portland cement & 18.7 & 4.5 & 3.4 & 65.9 & 1.3 & 0.8 & 0.2 & 4.3 \\
\hline Bentonite & 56.9 & 17.3 & 15.8 & 3.1 & 3.5 & 1 & 0.4 & - \\
\hline Silica flour & 99.7 & 0.2 & - & - & - & - & - & - \\
\hline
\end{tabular}

\section{Experimental methods}

\subsection{Basic physical properties}

Vacuum water saturation [9] was used for determination of the basic physical properties, specifically bulk density, matrix density and open porosity. Three samples with dimensions of $50 \times 50 \times 50 \mathrm{~mm}$ were measured. Water vacuum saturation method was based on Archimedes law and three different mass had to be determined for the calculation of basic physical properties. To remove physically bounded water and determination of dry mass, specimens were dried in a drying box kept at the temperature of $105{ }^{\circ} \mathrm{C}$. The second mass was the water saturated one. Samples were put into a desiccator with boiled distilled water and air was evacuated with vacuum pump. After removing samples from desiccator, their mass in the saturated state was measured. Finally, the mass of saturated samples under the water, so called the Archimedes mass was determined.

\subsection{Mechanical parameters}

The most important mechanical property of concrete is indisputably compressive strength. Their determination was performed according to the standard ČSN EN 12390-3 [10]. Six cubic samples with an edge of $150 \mathrm{~mm}$ were prepared, and the experiments were performed at the age of 28 days by the use of loading device EDB 400. The loading rate was constant up to the failure, when the ultimate force was determined.

The second measured mechanical property was flexural strengths. The experimental procedure followed the standard ČSN EN 12390-5 [11]. For this measurement six prismatic samples with dimensions $100 \times 100 \times 400 \mathrm{~mm}$ was used and the experiment was performed by the device MTS 100. The arrangement of measurement was the four-point bending test, which is more suitable due to the bigger area, where the maximal loading acts.

\section{Experimental results and discussions}

\subsection{Basic physical properties}

Obtained values of basic physical properties are summarized in Figure 1 and Figure 2. From the presented data, it can be seen that the presence of bentonite, probably thanks to its internal porosity, reduces the bulk density of concrete; specifically in range from $13 \%$ for RB1 up to $23 \%$ for RB4 in comparison with the reference mixture. The enlightening effect of bentonite is confirmed by the rise in the concrete open porosities; there is more than 3-times growth in values for RB4 compared to RBR. However, differences in matrix densities are negligible - within $1 \%$, and thus it can be concluded that bentonite's application has no effect on the matrix density of concrete. 


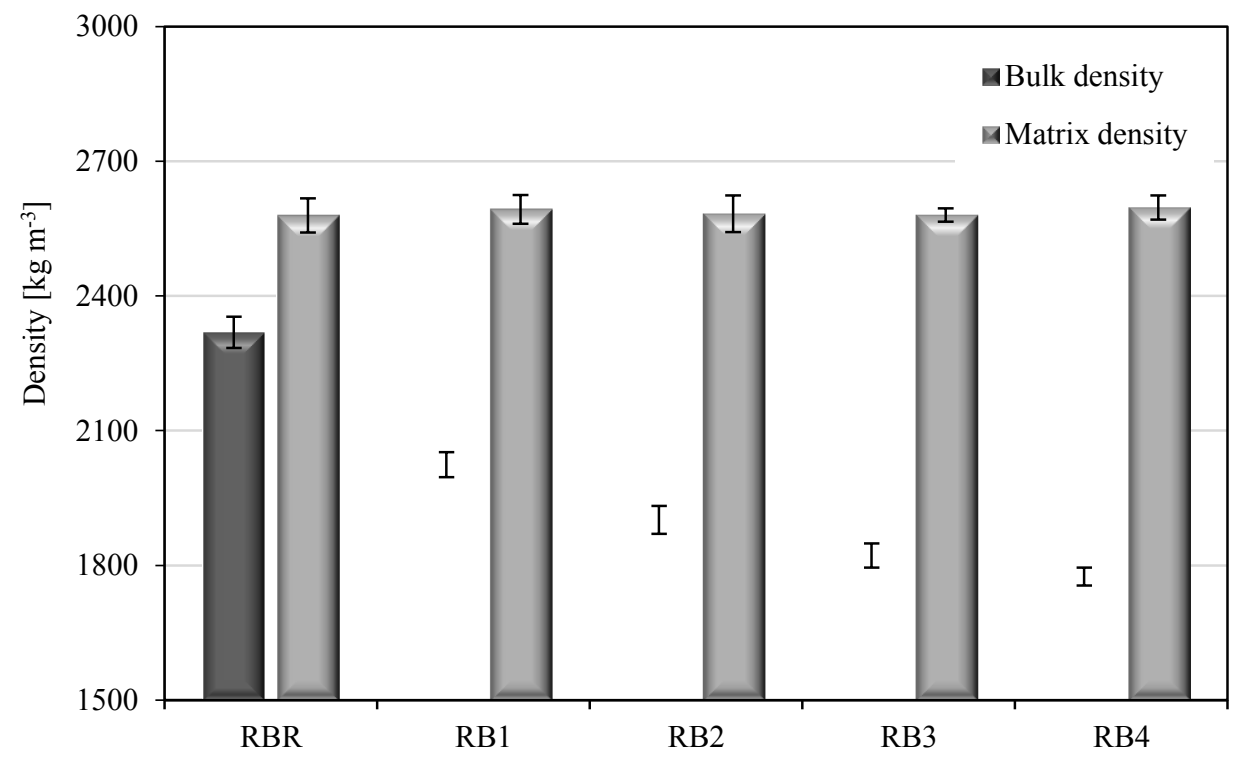

Fig. 1. Bulk density and matrix density of studied concretes

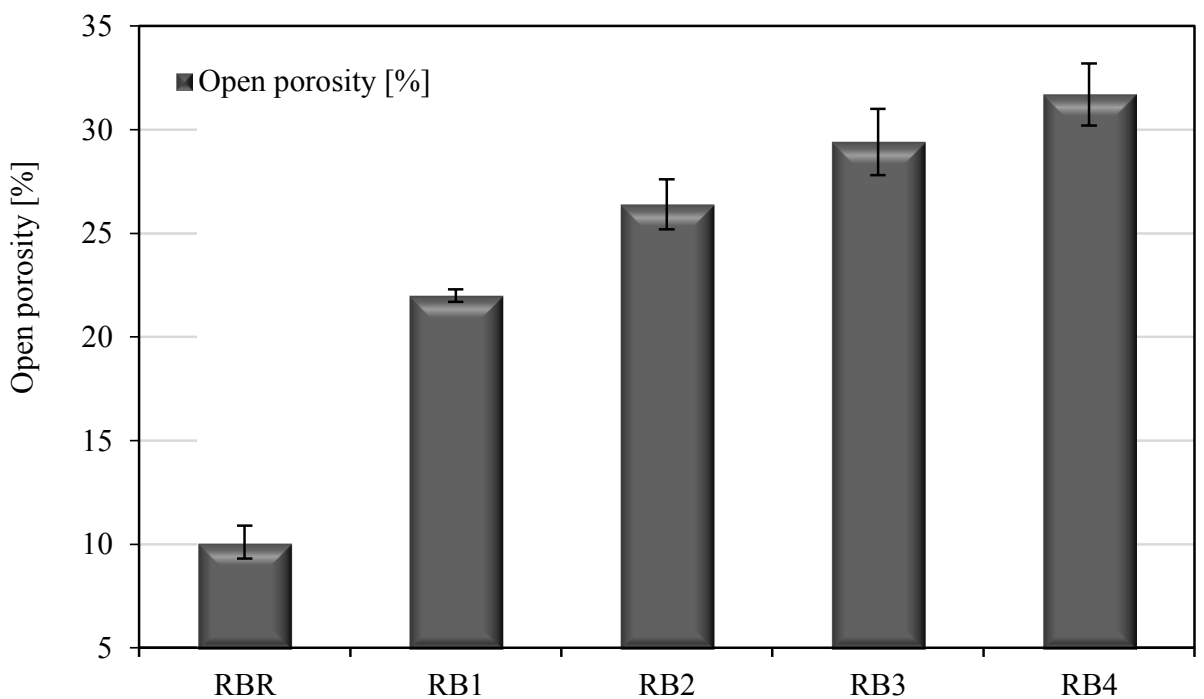

Fig. 2. Open porosity of studied concretes

\subsection{Mechanical parameters}

Results from mechanical testing are provided in Figure 3, displaying compressive strength and flexural strength respectively. The effect of bentonite presence on the compressive strength is vastly adverse. There was a huge drop in values by $70 \%$ between $\mathrm{RBR}$ and RB1 and further deceasing trend up to $86 \%$ reduction for RB4. As for flexural strength there was also a significant decline in values by $64 \%$ for RB1 with continuing 
falling to $80 \%$ for RB4. Such a massive strength reduction is in accordance with rise in porosities, as well as with the nature of raw material.

The minor or major decrease of compressive strength due to the bentonite (or montmorillonite respectively) was observed also by other researchers [8, 12, 13]. However, from the achieved results and the huge drop of mechanical strengths, it can be assumed, that not even $10 \%$ of bentonite acted as pozzolanic material, and its application in this way is not suitable. The further decrease when bentonite was replacing silica flour was less devasting, and from that perspective its application is possible. Moreover, the main contribution of bentonite in concrete mixture is not to improve the mechanical performance, but to improve the resistance to the transport of radionuclides, due to the bentonite sorption capacity.

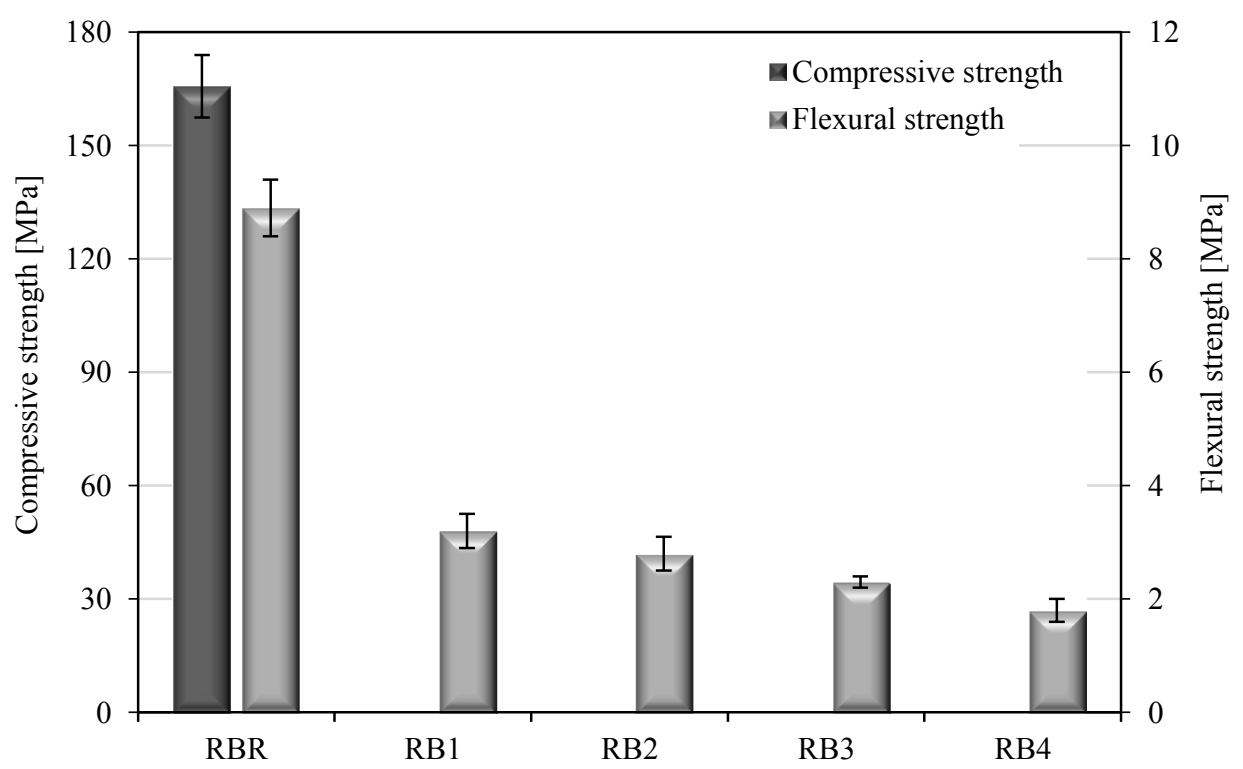

Fig. 3. Mechanical properties of studied concretes

\section{Conclusions}

Radioactive waste management is great issue to be addressed. Disposal of this waste brings new aspects and demands on the building materials used in the structure of radioactive barriers. One of the most important is resistivity of concrete structure to the radionuclide transport, and their possible inhabitation. Therefore, in this study bentonite with great sorption capacity was used as a part of concrete mixture. Five different mixtures were designed, and the impact of bentonite was assed. Primarily the basic physical properties as well as the mechanical strengths were examined. Utilization of bentonite lead to the growth of open porosity and thus also to the fall of mechanical parameters (both compressive strength as well as the flexural strength). From the achieved results can be concluded, that bentonite is not suitable as a pozzolanic material, because of a huge fall of mechanical strengths. However, its application as an aggregate replacement seems to be possible, because in this manner the fall of compressive strength and flexural strength is not so significant. Despite this the negative affect, the real benefits of the bentonite utilization should be in the sorption of radionuclides, which will be further investigated. 
This work was supported by the Czech Science Foundation, under project No $17-11635 \mathrm{~S}$.

\section{References}

1. Council directive 2013/59/EURATOM, Official Journal of the European Union L13, European Commission (2014).

2. J. Kotátková, J. Zatloukal, P. Reiterman, K. Koláŕ, J. Environ. Radioactiv. 178-179, 147-155 (2017).

3. The behaviours of cementitious materials in long term storage and disposal of radioactive waste: results of a coordinated research project, International atomic energy agency (Vienna, 2013).

4. M. I. Ojovan, Handbook of advanced radioactive waste conditioning technologies (Woodhead Publishing, Oxford, 2011).

5. S.S. Park, S.J. Kwon, S.H. Jung, Constr. Build. Mater. 29, 183-192 (2012).

6. A. Elkamash, M Elnaggar, M Eldessouky, J. Hazard. Mater. 136(2), 310-316 (2006).

7. I. Plecas, S. Dimovic, I. Smiciklas, Prog. Nucl. Energ. 48(6), 495-503 (2006).

8. I. Plecas, R. Pavlovic, S. Pavlovic, J. Nucl. Mater. 327(2-3), 171-174 (2004).

9. S. Roels, J. Carmeliet, H. Hens, O. Adan, H. Brocken, R. Černý, Z. Pavlík, C. Hall, K. Kumaran, L. Pel, R. Plagge, J. Therm. Envelope Build. Sci., 27(4), 307-325 (2004).

10. ČSN EN 12390-3, Testing hardened concrete - Part 3: Compressive strength of test specimens (Czech Standardization Institute, 2009).

11. ČSN EN 12390-5, Testing hardened concrete - Part 5: Flexural strength of test specimens (Czech Standardization Institute, 2009).

12. M. Z. Ahad, M. Ashraf, R. Kumar, M. Ullah, Thermal, Materials. 12(1), 14 (2018).

13. R. Fernandez, F. Martirena, K. L.Scrivener, Cement. Concrete. Res. 41(1), 113-122 (2011). 